\title{
Rapid green synthesis of silver nanoparticles by aqueous extract of seeds of Nyctanthes arbor-tristis
}

\author{
Shibani Basu $\cdot$ Priyankar Maji $\cdot$ Jhuma Ganguly
}

Received: 11 August 2014/Accepted: 27 January 2015/Published online: 13 February 2015

(C) The Author(s) 2015. This article is published with open access at Springerlink.com

\begin{abstract}
The present study explores that the aqueous extract of the seeds of Nyctanthes arbor-tristis (aka night jasmine) is very efficient for the synthesis of stable AgNPs from aqueous solution of $\mathrm{AgNO}_{3}$. The extract acts as both reducing (from $\mathrm{Ag}^{+}$to $\mathrm{Ag}^{0}$ ) and capping agent in the aqueous phase. The constituents in extract are mainly biomolecules like carbohydrates and phenolic compounds, which are responsible for the preparation of stable AgNPs within 20 min of reaction time at $25{ }^{\circ} \mathrm{C}$ using without any severe conditions. The synthesized silver nanoparticles were characterized with UV-Visible spectroscopy, FT-IR, XRD and SEM. UV-Vis spectroscopy analysis showed peak at $420 \mathrm{~nm}$, which corresponds to the surface plasmon resonance of AgNPs. XRD results showed peaks at (111), (200), (220), which confirmed the presence of AgNPs with face-centered cubic structure. The uniform spherical nature of the AgNPs and size (between 50 and $80 \mathrm{~nm}$ ) were further confirmed by SEM analysis.
\end{abstract}

Keywords Nyctanthes arbor-tristis . Aqueous extract . Green synthesis $\cdot$ Silver nanoparticles

\section{Abbreviations \\ AgNP Silver nanoparticle \\ $\mathrm{AgNO}_{3} \quad$ Silver nitrate}

\section{S. Basu · P. Maji · J. Ganguly $(\square)$}

Department of Chemistry, Indian Institute of Engineering

Science and Technology, Shibpur, Howrah 711103,

West Bengal, India

e-mail: jhumaiiest@gmail.com

S. Basu

e-mail: meetbasu.shibani@gmail.com

P. Maji

e-mail: priyankar4life@gmail.com $\begin{array}{ll}\text { FCC } & \text { Face-centered cubic } \\ \text { UV-Vis } & \text { Ultraviolet visible } \\ \text { FT-IR } & \text { Fourier transform infrared spectroscopy } \\ \text { SEM } & \text { Scanning electron microscopy } \\ \text { XRD } & \text { X-ray diffraction }\end{array}$

\section{Introduction}

The development of nanoparticle synthesis have got a remarkable recognition at present scenario because of the excellent implication of optical, chemical and biological properties. The diversity of metal nanoparticles (MPNs) showed various physiochemical and biochemical properties to design new devices and catalytic activity for important industrial reactions. The large number of techno-commercial products containing nanomaterials and their possible applications continue to grow exponentially (Luciana et al. 2011). The size, shape and surface morphology of nanoparticles play a most vital role in controlling the physical, chemical and biological properties of nanoparticles (D. Philip 2010). Among all nanoparticles, silver nanoparticles have potential applications in the fields of agriculture (Park et al. 2006), forensic science (C. Antonio 2008), chemistry ( $\mathrm{Li}$ et al. 2009), waste management, pollution control, solar cells, and biomedicine. Various chemicals and physical methodology are listed for the synthesis of nanoparticles such as chemical reduction (Kholoud et al. 2010), photochemical reduction (Kshirsagar et al. 2014; Scaiano et al. 2009), and electrochemical reduction (Roldán et al. 2013; Yanga et al. 2011). These processes sometimes depend on the toxic chemicals (such as solvent, reducing agent, capping agent) which may not be harmful for the synthesis of nanoparticles in industrial purposes but it is always expected to synthesize the 
nanoparticles in greener approach in the application of environmental and biological issues. Thus, there is a growing need to develop eco-friendly processes to avoid the use of toxic and hazardous chemicals in their synthesis (Vanaja and Annadurai 2013).

Over the past decade, increasing awareness and requirement of sustainable development about the environment has led to focus on 'green chemistry'. Utilization of non-toxic non-hazardous chemicals, environmentally benign solvents and renewable materials are some of the key issues that merit the important consideration in a green synthesis strategy (Vigneshwaran et al. 2006). Recently, researchers have initiated using bioactive molecules as templates for generation of inorganic structures and materials. The aqueous phase and the use of biocompatible materials as reducing and capping agents for the preparation of nanoparticles in different shapes and sizes and their stabilization will undoubtedly play a crucial role (Vigneshwaran et al. 2006).

Nyctanthes arbor-tristis is one of the well-known medicinal herbs of Indian origin. The extracts of the seeds, flowers and leaves possess various medicinal values, e.g. immunoenhancer, hepatoprotective, antimicrobial and anti-parasitological activities in vitro (Puri et al. 1994). Phytochemicals analysis of seeds showed the presence of phytosterols, phenolics compounds, tannins, flavonoids, cardiac glycosides, saponins and alkaloids. The phytochemical repertoire of $N$. arbor seeds with no toxicity made it a choice of interest enroute to green synthesis in the preparation of AgNPs by reduction of Ag salts (Suresh and Arunachalam 2012; Balasubramanian 2012; Khanapur et al. 2014). In accordance with the mentioned facts and relevant references, in the present study, we used aqueous extract of $N$. arbor-tristis seeds, which is low cost, non-toxic, environment friendly and having an excellent reducing capacity for the synthesis of AgNPs. The current studies showed the efficient approach of green synthesis for the preparation of AgNPs and their formation and morphology were analyzed and characterized by UV-Vis spectroscopy, FT-IR analysis, XRD and SEM analysis. The instrumental analysis shows a good agreement with each other for the synthesized AgNPs.

\section{Materials and methods}

\section{Materials}

The seeds of N. arbor-tristis (Fig. 1) were collected from the garden at the end of November. Silver nitrate was purchased from Merck Limited, India. Throughout the experiments, Milli Q water was used.

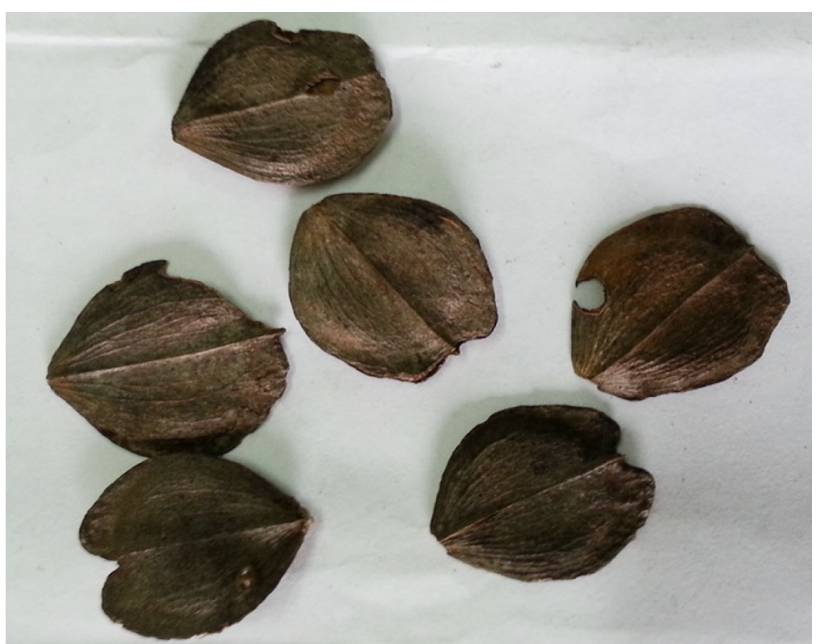

Fig. 1 Seeds of Nyctanthes arbor-tristis

Methods

Collection of sample, extraction and isolation

The dry seeds of $N$. arbor-tristis were collected, seeds separated from peel, dried and made into powdered form. The powdered samples were kept in water for $48 \mathrm{~h}$ at $25^{\circ} \mathrm{C}$ under continuous stirring condition. The crude aqueous extract was collected by centrifugation at 3,000 rpm for $15 \mathrm{~min}$.

\section{Synthesis of silver nanoparticles}

In a typical green reaction procedure, aqueous extract was added to $1 \mathrm{mM}$ aqueous $\mathrm{AgNO}_{3}$ solution with stirring at room temperature. The colorless $\mathrm{AgNO}_{3}$ solution was instantly turned into light to dark brown colouration after addition of aqueous extract.

\section{Characterization techniques}

\section{UV-Vis spectra technique}

The reduction of $\mathrm{Ag}^{+}$to $\mathrm{Ag}^{0}$ was observed by measuring the Absorbance in UV-Vis spectrum (Sun et al. 2001) at different time intervals with the aliquot reaction mixture and water used as blank. UV-Vis spectral analysis has been monitored by using a series 3000 double beam ultravioletVisible spectrophotometer (JASCO V360) at a resolution from 200 to $800 \mathrm{~nm}$.

XRD technique

X-ray diffraction (XRD) analysis of drop-coated films of synthesized. AgNPs were prepared for the determination of 
the type of crystallization. A Bruker D- 8 Advanced X-Ray diffractometer with $2 \theta=30-80^{\circ}$ scanning mechanism and Ni-filtered $\mathrm{Cu} \quad \mathrm{K} \propto \quad \mathrm{X}$-radiation with wavelength $1.540598 \AA$ used for this characterization.

\section{FT-IR spectroscopy}

FT-IR spectra were obtained on JASCO FT/IR-460 plus spectrometer. The synthesized AgNPs were mixed with $\mathrm{KBr}$ powder and pressed into a pellet for measurement. Background correction was made using a reference blank $\mathrm{KBr}$ pellet.

\section{SEM analysis}

Synthesized AgNPs were used for SEM analysis by fabricating a drop of suspension onto a clean electric stubs and allowing water to completely evaporate with platinum coating. SEM observations were carried out on a ZEISS EVO 18 electron microscope.

\section{Results and discussion}

UV-VIS absorbance analysis

Aqueous extract was added to $1 \mathrm{mM}$ aqueous $\mathrm{AgNO}_{3}$ solution with stirring at room temperature. The change of colouration occurred from light to dark brown suspension within 20 min of addition (Fig. 2). The aqueous extract behaved as both reducing (from $\mathrm{Ag}^{+}$to $\mathrm{Ag}^{0}$ ) as well as capping agent for nascent nanoparticles and the change of colouration indicated the formation of Silver

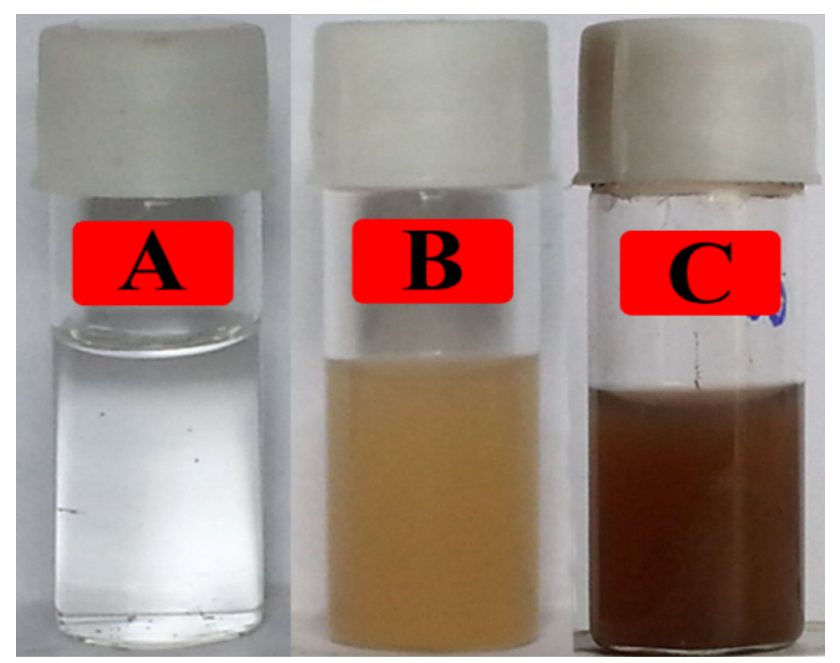

Fig. 2 Freshly prepared $\mathrm{AgNO}_{3}$ sol ( $A$ ), reaction mixture of $\mathrm{AgNO}_{3}$ and seed extract after 20 min $(B)$, reaction mixture of $\mathrm{AgNO}_{3}$ and seed extract after $5 \mathrm{~h}(C)$

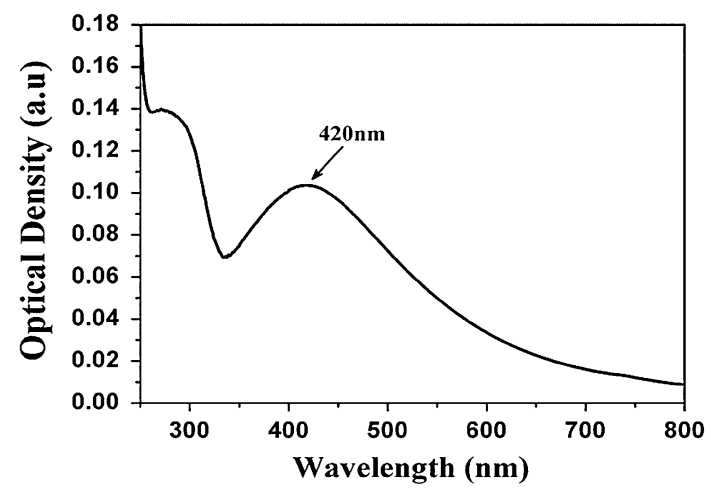

Fig. 3 UV-Vis absorption spectrum of synthesized AgNPs

nanoparticles. According to the distribution of size of nanoparticles, the synthesized AgNPs showed absorbance $\left(\lambda_{\max }\right)$ from 415 to $425 \mathrm{~nm}$ and the absorbance centered at $420 \mathrm{~nm}$, which corresponds to the wavelength of the surface plasmon resonance of AgNPs (Fig. 3). The absorbance $\left(\lambda_{\max }\right)$ also gives a more blue shift tendency (distribution of size $>50 \mathrm{~nm}$ ) along with prominent peak at $420 \mathrm{~nm}$ (distribution of size $=/<50 \mathrm{~nm}$ ) because of the presence of mixing of various sized nanoparticles. The SEM analysis predicts the distribution of size of AgNPs from 50 to $80 \mathrm{~nm}$, which is in good agreement with the absorbance observed in UV-Vis spectrophotometer (Zahir and Rahuman 2012).

\section{XRD analysis}

Analysis of X-ray diffraction pattern (XRD) was performed to confirm the crystalline nature of the AgNPs. The XRD pattern showed numbers of Bragg reflections that may be indexed on the basis of the FCC structure of silver. X-ray diffraction pattern (XRD) was recorded for the synthesized AgNPs (Fig. 4). Three distinct peaks at $2 \theta$ values of $38.378^{\circ}, 44.608^{\circ}$ and $64.573^{\circ}$ were indexed with the planes (111), (200), and (220) for FCC silver as per the JCPDS card no. 04-0783. The well-resolved and intense XRD pattern clearly showed that the AgNPs formed by the reduction of $\mathrm{Ag}^{+}$ions using aqueous extract are crystalline in nature. The low intense peak at $77.34^{\circ}$ belongs to (311) plane. Similar results were reported for AgNPs in the literature. (Jagtap and Bapa 2013; Das et al. 2013; Edison and Sethuraman 2013; Raman et al. 2012; Zayed et al. 2012; Dipankar and Murugan 2012; Bindhu and Umadevi 2013; Guidelli et al. 2011).

\section{FT-IR analysis}

The dual role of the plant extract as a bioreductant and capping agent was confirmed by FT-IR analysis of 


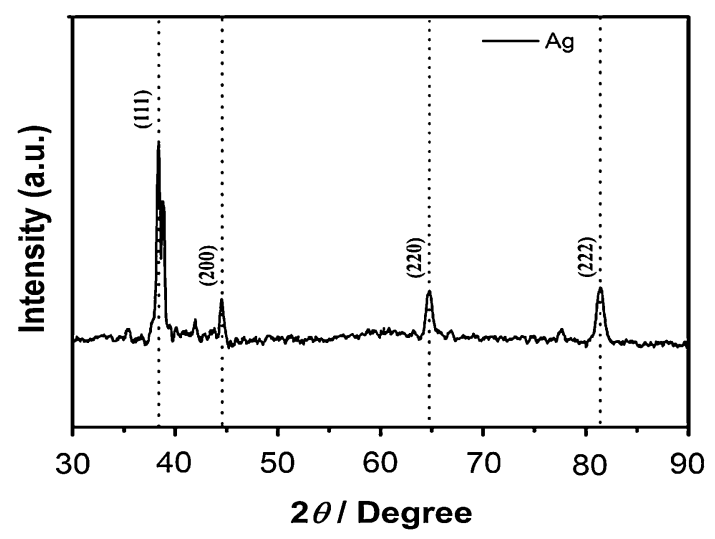

Fig. 4 X-ray diffraction pattern of the green synthesized silver nanoparticles AgNPs

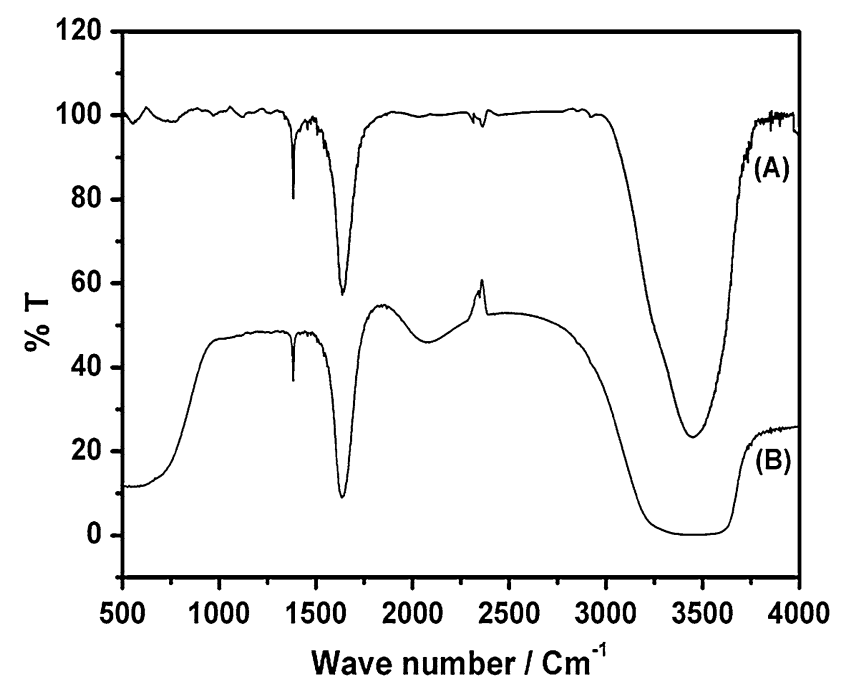

Fig. 5 FT-IR pattern of the ( $A$ water extract of $N$. arbor seed, $B$ synthesized AgNP)

AgNPs. The sample for the infrared analysis was carefully prepared to exclude any possibility of the presence of any unbound plant extract residue. The similarities between the spectra (Fig. 5), with some marginal shifts in peak position, clearly indicate the presence of the residual plant extract in the sample as a capping agent to the AgNPs. The peak (Fig. 5) observed at $3,456 \mathrm{~cm}^{-1}$ in seed extract is characteristic of the $\mathrm{O}-\mathrm{H}$ stretching. The band at $1,644 \mathrm{~cm}^{-1}$ corresponds to amide $\mathrm{C}=\mathrm{O}$ stretch. In the case of nanoparticles, a large shift in the absorbance peak with decreased band intensity was observed from 3,494 to $3,312 \mathrm{~cm}^{-1}$ (Fig. 5) implying the binding of silver with hydroxyl groups of the extract. The spectra also show a shift at $1,637 \mathrm{~cm}^{-1}$ related to amide I linkages, validates that free amino $(-\mathrm{NH} 2)$ or carboxylate $(-\mathrm{COO})$ groups in compounds of the seed extract have interacted with AgNPs (Khalil 2013).

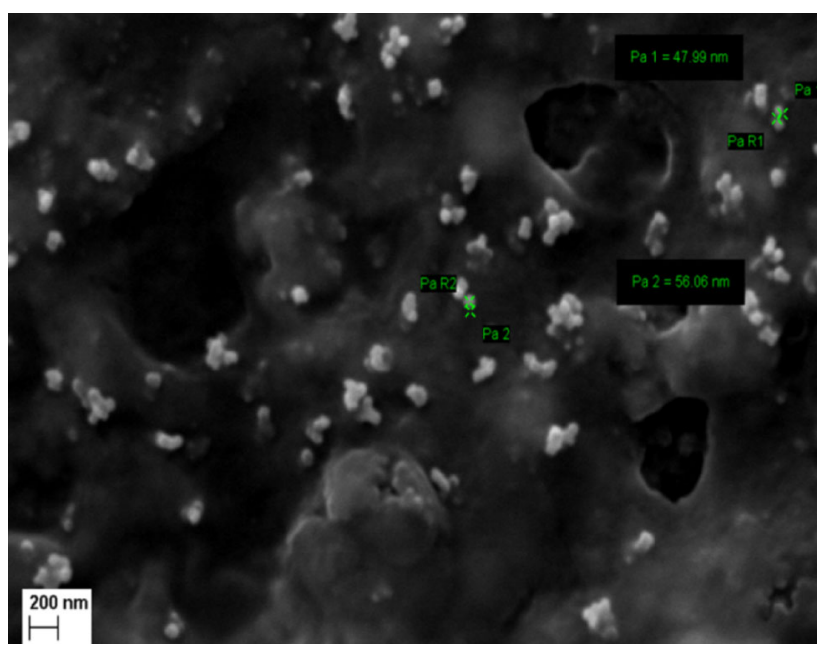

Fig. 6 SEM images of synthesized AgNPs

SEM analysis for AgNPs

The analysis of the scanning electron microscopy (SEM) images predicts the formation and the morphology of stable silver nanoparticles obtained from the current green approach. The images showed the presence of both individual as well as the aggregated AgNPs. The AgNPs are mainly uniform spherical shaped with the average range of particle size distribution from 50 to $80 \mathrm{~nm}$. The surface plasmon resonance $\left(\lambda_{\max }\right)$ observed in the UV-Vis spectra for the distribution of size is excellent resemblance with the SEM data (Fig. 6).

\section{Conclusions}

The rapid green approach is performed for the preparation of stable AgNPs applying the aqueous extract of the seed of $N$. arbor-tristis. The aqueous extract is used both as reducing and capping agent. The formation of AgNPs (from $\mathrm{Ag}^{+}$to $\mathrm{Ag}^{0}$ ) is confirmed by the observed surface Plasmon resonance $\left(\lambda_{\max }\right.$ at $415-425 \mathrm{~nm}$ centered at $\left.420 \mathrm{~nm}\right)$ in UV-Vis spectra. The analysis of SEM predicts the uniform spherical shape along with the distribution of particle size within the range $50-80 \mathrm{~nm}$. The XRD shows crystalline nature of FCC silver with the planes (111), (200), and (220). Moreover, its ample sources and low cost make $N$. arbor-tristis seed extract potentially striking for the upscaling of metallic non-materials to explore various catalytic and biomedical applications.

Acknowledgments The authors are grateful for financial supports from the Department of Biotechnology (DBT) for project code BT/ PR6195/FNS/20/648/2012. 
Open Access This article is distributed under the terms of the Creative Commons Attribution License which permits any use, distribution, and reproduction in any medium, provided the original author(s) and the source are credited.

\section{Reference}

Abou Kholoud MM, El-Noura Ala'a Eftaihab, Al-Warthanb Abdulrhman, Reda AA (2010) Synthesis and applications of silver nanoparticles. Arab J Chem 3(3):135-140. doi:10.1016/j.arabjc. 2010.04.008

Balasubramanian M (2012) Study on phytochemical screening and antibacterial activity of Nyctanthes-arbor-tristis. J. Chem Pharm Res 4(3): 1686

Bindhu MR, Umadevi M (2013) Synthesis of monodispersed silver nanoparticles using Hibiscus cannabinus leaf extract and its antimicrobial activity. Spectrochim Acta A Mol Biomol Spectrosc 101:184-190

Cantu Antonio A (2008) Nanoparticles in forensic science. Proc of SPIE 7119:71190F. doi:10.1117/12.800784

Das J, Paul DM, Velusamy P (2013) Sesbaniagrandiflora leaf extract mediated green synthesis of antibacterial silver nanoparticles against selected human pathogens. Spectrochim Acta A Mol Biomol Spectrosc 104:265-270

Dipankar C, Murugan S (2012) The green synthesis, characterization and evaluation of the biological activities of silver nanoparticles synthesized from Iresineherbstii leaf aqueous extracts. Colloids Surf B Biointerfaces 98:112-119

Edison TJ, Sethuraman MG (2013) Iogenic robust synthesis of silver nanoparticles using Punica granatum peel and its application as a green catalyst for the reduction of an anthropogenic pollutant 4-nitrophenol. Spectrochim Acta A Mol Biomol Spectrosc 104:262-264

Guidelli EJ, Ramos AP, Zaniquelli ME, Baffa O (2011) Green synthesis of colloidal silver nanoparticles using natural rubber latex extracted from Hevea brasiliensis. Spectrochim Acta A Mol Biomol Spectrosc 82:140-145

Jagtap U, Bapa VA (2013) Green synthesis of silver nanoparticles using artocarpus heterophyllus lam. Seed extract and its antibacterial activity. Ind Crop Prod. 46:132-137

Khalil M.M.H. (2013) Green synthesis of silver nanoparticles using olive leaf extract and its antibacterial activity. Arab J Chem doi:10.1016/j.arabjc.2013.04.007

Khanapur M, Avadhanula RK, Oruganti HS (2014) In Vitro antioxidant, antiproliferative, and phytochemical study in different extracts of Nyctanthes arbortristis flowers. BioMed Research International 291271:10. doi:10.1155/2014/291271

Kshirsagar P, Sangaru SS, Brunetti V, Malvindi MA (2014) Synthesis of fluorescent metal nanoparticles in aqueous solution by photochemical reduction. Nanotechnology 25(4):045601. doi:10.1088/0957-4484/25/4/045601
Li H, Li F, Wang L, Shengv J, Xin Z, Zhao L (2009) Effect of nanopacking on preservation quality of Chinese jujube (Ziziphus jujube Mill. Var. inermis (Bunge) Rehd). Food Chem 114:547-552. doi:10.1016/j.foodchem.2008.09.085

Luciana D, Panzarini E, Serra A, Buccolieri A, Manno D (2011) Synthesis and in vitro cytotoxicity of glycans-capped silver nanoparticles. Nanomater. nanotechnol 1(1):58-64

Park HJ, Sung HK, Kim HJ, Choi SH (2006) A new composition of nanosized silica-silver for control of various plant diseases. Plant Pathol J 22:295-302

Philip D (2010) Green synthesis of gold and silver nanoparticles using Hibiscus rosa sinensis. Physica E: Low-Dimen Syst Nanostructures 42(5):1417-1424. doi:10.1016/j.physe.2009.11.081

Puri A, Saxena R, Saxena RP, Saxena KC, Srivastava V, Tandon JS (1994) Immunostimulant activity of Nyctanthes arbor-tristis $L$. J Ethnopharmacol 42(1):31-37

Raman N, Sudharsan S, Veerakumar V, Pravin N, Vithiya K (2012) Pithecellobium dulce mediated extra cellular green synthesis of larvicidal silver nanoparticles. Spectrochim Acta A 96:1031-1037

Roldán MV, Pellegri N, Sanctis OD (2013) Electrochemical method for AG-PEG nanoparticles synthesis. J Nanoparticles 524150:7. doi: $10.1155 / 2013 / 524150$

Scaiano JC, Billone P, Gonzalez CM, Maretti L, Marin ML, McGilvray KL, Yuan N (2009) Photochemical routes to silver and gold nanoparticles. Pure Appl Chem 81(4):635-647. doi:10. 1351/PAC-CON-08-09-11

Sun YP, Atorngitjawat P, Meziani MJ (2001) Preparation of silver nanoparticles via rapid expansion of water incarbon dioxide microemulsion into reductant solution. Langmuir 17:5707-5710

Suresh V, Arunachalam G (2012) Pharmacognostical and preliminary phytochemical studies of bark of nyctanthes arbor-tristis linn. Int J Pharm Sci 4(Suppl 1):356-363

Vanaja M, Annadurai G (2013) Coleus aromaticus leaf extract mediated synthesis of silver nanoparticles and its bactericidal activity. Appl Nanosci 3:217-223. doi:10.1007/s13204-0120121-9

Vigneshwaran N, Nachane RP, Balasubramanya RH (2006) Varadarajan PV (2006) A novel one-pot 'green' synthesis of stable silver nanoparticles using soluble starch. Carbohydr Res 341(12):2012-2018. doi:10.1016/j.carres.04.042

Yanga J, Shengyuan D, Jianping L, Jub H, Gunasekarana S (2011) Electrochemical synthesis of reduced graphene sheet-AuPd alloy nanoparticles composites for enzymatic biosensing. Biosens Bioelectron 29:159-166. doi:10.1016/j.bios.2011.08. 011

Zahir AA, Rahuman AA (2012) Evaluation of different extracts and synthesised silver nanoparticles from leaves of euphorbia prostrata against haemaphysalisbispinosa and hippoboscamaculata. Vet Parasitol 187:511-520

Zayed MF, Eisa WH, Shabaka AA (2012) Malvaparviflora extract assisted green synthesis of silver nanoparticles. Spectrochim Acta A Mol Biomol Spectrosc 98:423-428 